\title{
Evaluation of DC-link Decoupling Using Electrolytic or Polypropylene Film Capacitors in Three-Phase Grid-Connected Photovoltaic Inverters
}

\author{
Baburaj Karanayil ${ }^{(1)}$, Vassilios G. Agelidis ${ }^{(1)}$ and Josep Pou ${ }^{(1)(2)}$ \\ ${ }^{(1)}$ Australian Energy Research Institute, The University of New South Wales, UNSW Sydney, NSW 2052, Australia \\ ${ }^{(2)}$ Terrassa Industrial Electronics Group, Technical University of Catalonia, Catalonia, Spain \\ Email: k.baburaj@unsw.edu.au, vassilios.agelidis@unsw.edu.au, j.pou@unsw.edu.au
}

\begin{abstract}
The life expectancy and long term reliability of grid-connected three-phase photovoltaic $(\mathrm{PV})$ inverters can be increased by replacing the conventional electrolytic film capacitors by metallized polypropylene film capacitors.

This paper presents a detailed evaluation of a three-phase gridconnected PV inverter performance when replacing the electrolytic capacitor with a minimum value of metallized polypropylene film capacitor-one. The minimum de bus capacitance leads to larger voltage ripples. However, such ripples were found to be within acceptable limits to run the inverter satisfactorily. Simulation results are presented for a $15-\mathrm{kW}$ gridconnected inverter at nominal voltage of $700 \mathrm{~V}$ dc and experimental results are provided for a $3.0-\mathrm{kW}$ system at a nominal voltage of $400 \mathrm{~V}$ dc, built in the laboratory.
\end{abstract}

Index Terms - Photovoltaic systems, grid-connected inverters, electrolytic capacitor

\section{INTRODUCTION}

The typical lifetime of commercial photovoltaic (PV) panels is about 25 years [1],[2]. However, the typical operating life of the PV inverters processing energy generated by PV panels is limited by the operating life of their individual components. The operating life of commercial electrolytic capacitors used as dc-link intermediate energy storage is only about 10 years presenting a reliability related weak link in the PV system [3],[4].

The life expectancy and long term reliability of gridconnected three-phase PV-inverters can be increased by replacing the conventional electrolytic film capacitors by metallized polypropylene film capacitors [5]. Film capacitors have a lower capacitance per unit volume compared to the electrolytic counterparts, and therefore a direct replacement will lead to a very large and expensive solution. The biggest design limitation for electrolytic capacitors in the inverter has been the amount of ripple current that the electrolytic capacitor can sustain. Typically, any inverter design ends up with an electrolytic capacitor many times larger because of this restriction.

Electrolytic capacitors have been used in industrial applications for hard switched inverters for many years. The dc-link capacitor $C_{d c}$ in the grid-connected PV inverter shown

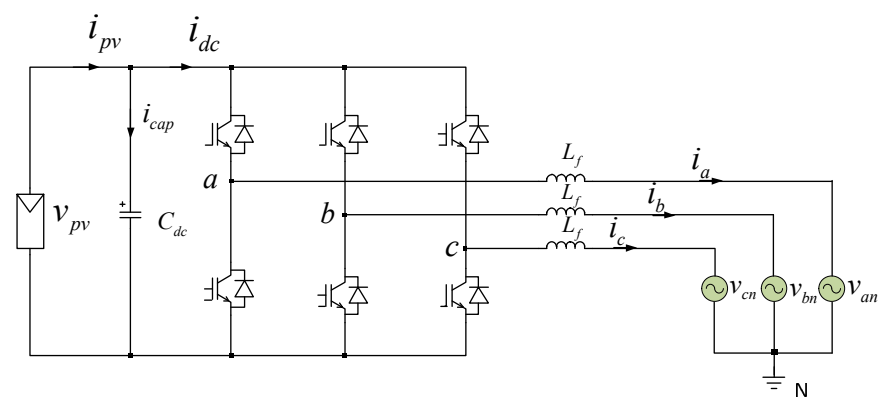

Fig. 1. Three-phase grid-connected PV-inverter.

in Fig. 1 is a load balancing energy storage element between the PV panel and the three-phase grid. This capacitor is connected in parallel to the PV panel to maintain a stiff dc-link voltage across the voltage source inverter (VSI). An electrolytic capacitor mostly used in industrial applications offers a greater capacitance per unit volume compared to a polyester / polypropylene film capacitor. It is easy and affordable to install electrolytic capacitors for decoupling between the input and output of the inverter as they cost less per Joule. They produce more heating inside as they have high equivalent series resistance (ESR). The major drawback of these capacitors is their limited operating life. Over long time, the liquid electrolyte evaporates through the rubber sleeves of the capacitor, degrading the capacitance. The effect can be compensated by oversizing the capacitors by design. However, the lifetime limitation still exists. The film capacitors have lower ESR thus producing less heating and having longer lifetime. The disadvantage of film capacitors is their low capacitance per volume ratio (approximately 20 times lower than electrolytic one) and thus the higher cost per Joule. A direct replacement is therefore not feasible in terms of cost and size. It is hence critical to find out solutions to improve the operating lifetime of inverters using film capacitors with a compromise.

In PV applications, the voltage ripple at the inverter input has to be kept small in order to assure stable operation in the maximum power point (MPP) of the PV modules. Many efforts have been reported in the technical literature to replace electrolytic capacitors by film counterparts. A very general solution for decreasing the capacitance in a single-phase PV- 
inverter, which is independent of the inverter topology is the parallel active filter presented in [6]. The dc-link capacitor is separated into two parts. The capacitors are connected via bidirectional dc-dc converter, allowing a different voltage at both of them. The dc/dc converter is operated in a way which keeps the dc-link voltage constant, while the voltage of the second capacitor with a larger ripple with larger part of the stored energy. The dc-link capacitance requirements for a single-phase multi-string PV inverter are compared in [7]. In the two-stage inverter, the boost converter decouples the PV string from the output inverter, allowing use of a smaller dclink capacitor. The dc-link capacitor for the single-stage inverter was found at least five times the size of the required capacitor in the two-stage inverter in order to retain its advantage of having higher conversion efficiency [7]. The bulky electrolytic capacitors in ac PV interface can be replaced with small film capacitors with dc distribution to fully guarantee the lifetime of the PV system. A boundary conduction mode (BCM) operated single-phase boost converter at $100 \mathrm{kHz}$ with soft switching of semiconductor devices has been presented in [8]. Only a small capacitance which is one thousandth of the ac case is enough to keep the voltage variation within $0.7 \mathrm{~V}$. However, the above schemes were studied and reported for single-phase PV-inverters.

\section{CALCUlation OF THE DC Link CAPACITOR}

The selection of dc-link capacitors for high performance inverter applications is reported in [9]. A detailed analysis and evaluation of dc-link capacitors for an $80-\mathrm{kW}$ electric vehicle drive system is reported in [10].

The PV current $i_{p v}$ is the sum of the capacitor current $i_{c a p}$ and the dc-link current $i_{d c}$ as shown in Fig. 1. These current waveforms are affected by the load power factor $\cos \varphi$ and the inverter modulation index $m$. Based on the synthesis of inverter current modulation [11], the root-mean-square (RMS) capacitor ripple current can be expressed by

$$
I_{c a p, R M S}=I_{N, R M S} \sqrt{\left[2 m\left\{\frac{\sqrt{3}}{4 \pi}+\cos ^{2} \phi\left(\frac{\sqrt{3}}{\pi}-\frac{9}{16} m\right)\right\}\right]}
$$

where $m$ is the modulation index, $I_{N}$ is the output phase current and $\phi$ is the phase delay of the inverter output current with respect to the fundamental voltage.

\section{A. Simulation Study}

For a $15-\mathrm{kW}$ load to be connected to a $415-\mathrm{V}$ three-phase voltage grid, the maximum current stress in the capacitor is calculated as $13.56 \mathrm{~A}$ for $m=0.612$, and $\phi=0$.

The electrolytic capacitor $5600 \mu \mathrm{F} / 450 \mathrm{~V}$ (EPCOS B43456
5568 ) is selected which has $I_{a c, R}=22.1 \mathrm{~A}$ at $10 \mathrm{kHz}$. In order to meet the capacitor ripple current rating to operate at $800 \mathrm{~V}$ dc, two $5600-\mu \mathrm{F}$ capacitors should be connected in series. Therefore, the equivalent capacitance is $2800 \mu \mathrm{F}$.

The value of the minimum capacitance to meet the $13.56 \mathrm{~A}$ ripple current and producing a $V_{\text {ripple }}$ will be:

$$
C_{d c \min }=\frac{I_{r m s}}{V_{\text {ripple }} \times 2 \times \pi \times f_{s}}
$$

for $V_{\text {ripple }}$ of $5 \mathrm{~V}, I_{r m s}=13.56 \mathrm{~A}, f_{s}=10 \mathrm{kHz}, C_{d c \min }=43.16 \mu \mathrm{F}$. The next commercially available capacitor of $47 \mu \mathrm{F}$ is used in the simulation.

\section{B. Experimental Study}

For a $3-\mathrm{kW}$ load at $200 \mathrm{~V}$ (line-to-line) grid voltage, the maximum current stress in the capacitor is calculated as 5.63 A for $m=0.612$, and $\phi=0$. The electrolytic capacitor $1500 \mu \mathrm{F} /$ $450 \mathrm{~V}$ (EPCOS B43456 5158 has $\mathrm{I}_{\mathrm{ac}, \mathrm{R}}=8.45 \mathrm{~A}$ at $10 \mathrm{kHz}$. In order to meet the capacitor ripple current rating to operate at $800 \mathrm{~V}$ dc, the two $1500-\mu \mathrm{F}$ capacitors should be connected in series. Therefore, the equivalent capacitance is $750 \mu \mathrm{F}$. However, two $2200-\mu \mathrm{F}$ capacitors are connected in the experimental set-up. As per (2), for a $V_{\text {ripple }}$ of $4 \mathrm{~V}, I_{r m s}=5.63$ $\mathrm{A}$ and $f_{s}=10 \mathrm{kHz}, C_{d c}$ min $=22.4 \mu \mathrm{F}$. AVX brand FFVE6C0476K, 900V dc $47 \mu \mathrm{F}$ metallized polypropylene film capacitor is used in the experiment set-up.

\section{CONTROL STRATEGY FOR THE GRID-CONNECTED PV- INVERTER}

Fig. 2 shows the control scheme of the grid-connected PV inverter. In order to decouple the active and reactive power controls, the synchronous rotating $d-q$ reference frame is applied for developing the controllers. A synchronous reference frame phase-locked loop (SRF-PLL) [12] is used to synchronize the $d$-axis with the grid voltage vector. The $d$ channel current loop allows the control of active power that is supplied by the PV inverter. The reactive power is controlled by the $q$-axis current controller. To minimize the inverter power losses, unity power factor at the output of the inverter is desirable. Hence, a null reference $i_{q}^{*}$ for the reactive current loop is chosen. The $i_{d}$ and $i_{q}$ current references are generated by the outer control loops imposed by the dc voltage and reactive power references respectively. Two inner control loops regulate the $i_{d}$ and $i_{q}$ currents respectively where the coupling currents are compensated by feed forward terms as it can be observed in Fig. 2. An outer voltage loop maintains the PV panels' voltage close to a desired reference $v_{d c}{ }^{*}$, which is calculated by the Maximum Power Point Tracking (MPPT) algorithm to extract the maximum power from the PV panels. 


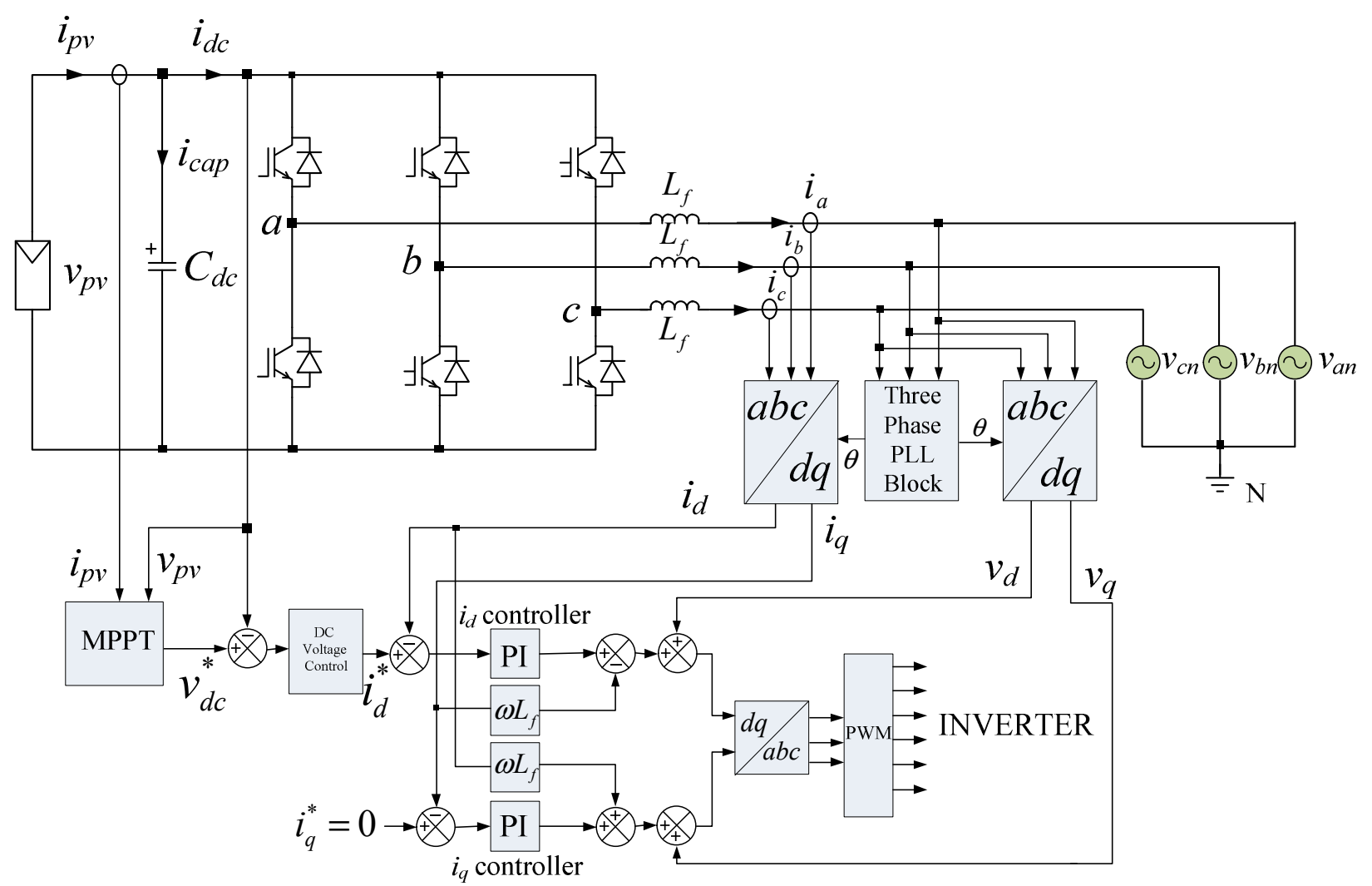

Fig. 2. Schematic of the control block diagram for three-phase grid-connected PV-inverter with $d q$ control.

TABLE I. PARAMETERS OF THE Three-Phase PV-INVERTER UNDER SIMULATION STUDY

\begin{tabular}{|l|c|c|}
\hline Rated power of PV array & $P_{\max }$ & $15600 \mathrm{~W}$ \\
\hline $\begin{array}{l}\text { Number of BP365 65W PV modules in the } \\
\text { string (series modules) }\end{array}$ & & 40 \\
\hline Number of strings in parallel & & 6 \\
\hline Open circuit voltage of PV array & $V_{o c}$ & $868 \mathrm{~V}$ \\
\hline Voltage at maximum power $P_{\max }$ & $V_{m p}$ & $704 \mathrm{~V}$ \\
\hline Current at maximum power $P_{\max }$ & $I_{m p}$ & $22.14 \mathrm{~A}$ \\
\hline $\begin{array}{l}\text { DC capacitors (electrolytic) } \\
\text { EPCOS type 2 x B43456 A5568, 5600 } \mu \mathrm{F} \text { in series }\end{array}$ & $C_{d c}$ & $2800 \mu \mathrm{F}$ \\
\hline $\begin{array}{l}\text { DC capacitors (metallized polypropylene film) } \\
\text { AVX type FFVE6C0476K, 900V dc }\end{array}$ & $C_{d c}$ & $47 \mu \mathrm{F}$ \\
\hline External line inductor & $L_{f}$ & $5 \mathrm{mH}$ \\
\hline Inverter switching frequency & $f_{s}$ & $10 \mathrm{kHz}$ \\
\hline
\end{tabular}

\section{SIMULATION RESUlts}

The grid-connected three-phase inverter with a $15-\mathrm{kW}$ PV module has been studied with simulations for steady state and transient behaviors in a MATLAB-PLECS software environment. The parameters of the system used for modeling are listed in Table I. Two different configurations are studied: one with a $2800-\mu \mathrm{F}$ electrolytic capacitor and the other one with a $47-\mu \mathrm{F}$ film capacitor. The objective is to optimize the ac ripple in the dc bus voltage, the RMS ripple current through the capacitor, the ripple current in the PV module and use the minimum capacitance possible which can still perform as a grid-connected system.

\section{A. Steady State}

\section{Results with $2800-\mu F$ Electrolytic Capacitor}

The 15-kW PV module with specifications in Table I provides the input to the three-phase inverter and the output is connected to the $415 \mathrm{~V}, 50 \mathrm{~Hz}$ grid. The grid voltage $v_{a n}$, the grid current $i_{a}$ and PV module current $i_{p v}$ are recorded when the PV module feeds $15 \mathrm{~kW}$ to the grid, as shown in Fig. 3. The ripple voltage across the capacitor, current $i_{c a p}$ and the dc bus voltage $v_{p v}$ are recorded as shown in Fig. 4. The ripple voltage across the capacitor is less than $0.2 \mathrm{~V}$ at $700 \mathrm{~V} \mathrm{dc}$ as seen in Fig. 4(a). The capacitor current $i_{\text {cap }}$ has a peak-to-peak value of 27 A as seen in Fig. 4 (b).

\section{Results with 47- $\mu$ F Film Capacitor}

Two EPCOS $5600-\mu \mathrm{F}$ electrolytic capacitors connected in series are replaced by one AVX type FFVE6C0476K, 900V dc $47-\mu \mathrm{F}$ film capacitor in the inverter and the steady state measurements are repeated as taken for the case of the 2800$\mu \mathrm{F}$ electrolytic capacitor. The grid voltage $v_{a n}$, grid current $i_{a}$ and the PV module current $i_{p v}$ are recorded when the PV module feeds $15 \mathrm{~kW}$ to the three-phase grid as shown in Fig. 5. The dc voltage and ac ripple voltage across the capacitor and the capacitor current $i_{c a p}$ are recorded as indicated in Fig. 6 . The ripple voltage at $700 \mathrm{~V}$ dc bus is close to $10 \mathrm{~V}$, which is $1.42 \%$ as seen in Fig. 6(a). The capacitor current has a larger ripple of $60 \mathrm{~A}$ as seen in Fig. 6(b). 


\section{B. Transient}

The transient performance of the grid-connected inverter is verified for a solar irradiance change from $0.5 \mathrm{~kW} / \mathrm{m}^{2}$ to 1.0 $\mathrm{kW} / \mathrm{m}^{2}$. These results are recorded for two cases, when the inverter uses the $2800-\mu \mathrm{F}$ electrolytic capacitor and then replaced by the $47-\mu \mathrm{F}$ film capacitor.

\section{Results with 2800- $\mu$ F Electrolytic Capacitor}

The grid voltage $v_{a n}$, grid current $i_{a}$ and the input power supply current $i_{p v}$ are recorded when the solar irradiance increases from

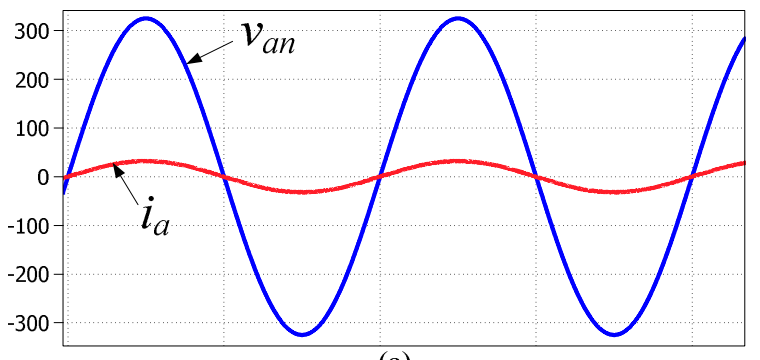

(a)

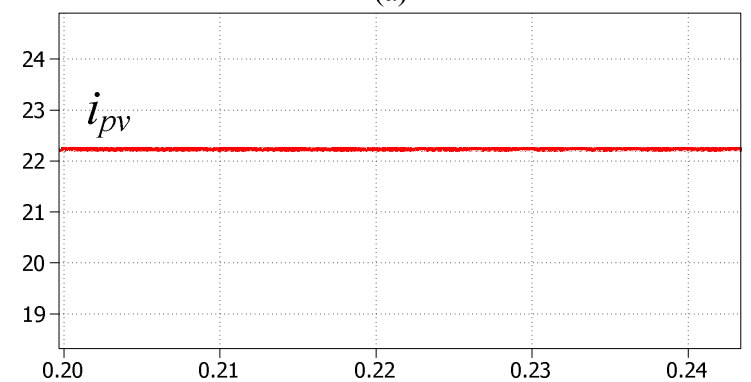

(b)

time(seconds)

Fig. 3. Simulation results Case $\mathrm{I}-C_{d c}$ is $2800-\mu \mathrm{F}$ electrolytic capacitor: (a) grid voltage $v_{a n}(\mathrm{~V})$ and grid current $i_{a}(\mathrm{~A})(\mathrm{b})$ PV array current $i_{p v}(\mathrm{~A})$.
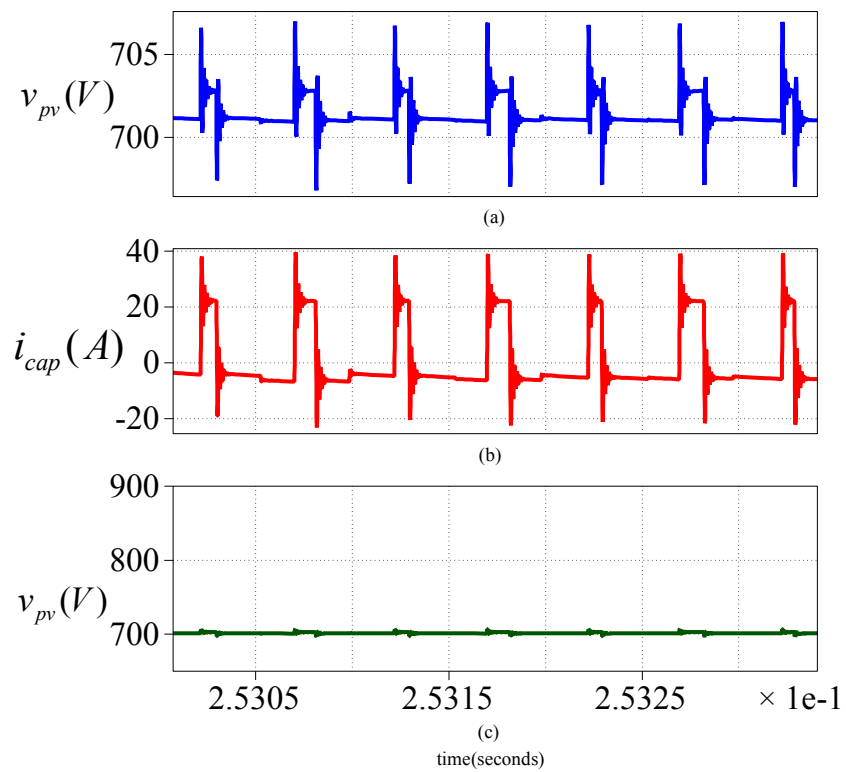

Fig. 4. Simulation results Case $\mathrm{I}-C_{d c}$ is $2800-\mu \mathrm{F}$ electrolytic capacitor: (a) detailed view of dc-link voltage showing the ripple (b) capacitor current and (c) dc-link voltage.
$0.5 \mathrm{~kW} / \mathrm{m}^{2}$ to its rated value $1.0 \mathrm{~kW} / \mathrm{m}^{2}$. The results are shown in Fig. 7. It is observed that the grid current undergoes a smooth transition.

\section{Results with 47- $\mu$ F Film Capacitor}

The transient performance of the grid-connected inverter is compared after replacing the $2800-\mu \mathrm{F}$ electrolytic capacitor with a $47-\mu \mathrm{F}$ film capacitor. The grid voltage $v_{a n}$, grid current $i_{a}$ and the input power supply current $i_{p v}$ are recorded when the solar irradiance increases from $0.5 \mathrm{~kW} / \mathrm{m}^{2}$ to its rated value $1.0 \mathrm{~kW} / \mathrm{m}^{2}$. The results are shown in Fig. 8. The grid current transition is very smooth even in this case.
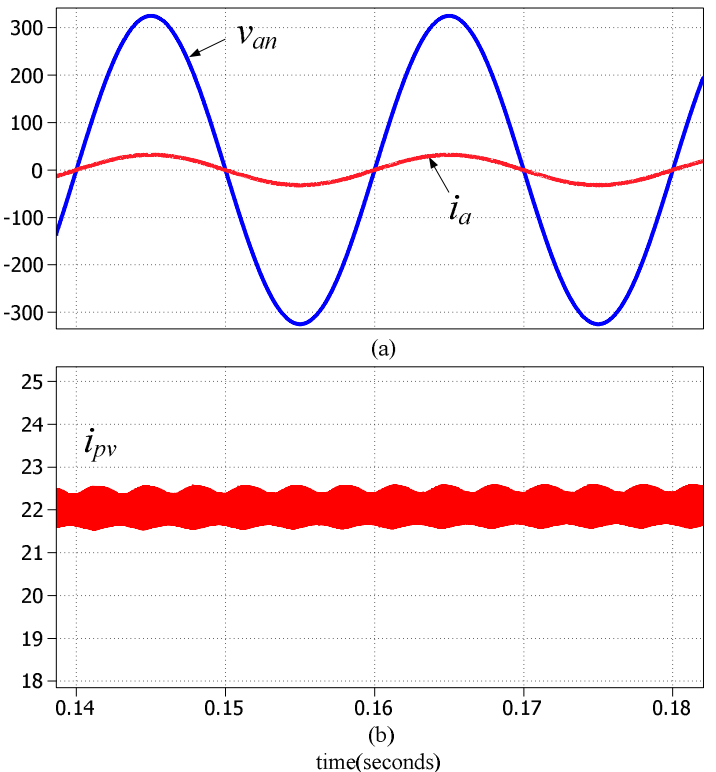

Fig. 5. Simulation results Case II $-C_{d c}$ is $47-\mu \mathrm{F}$ film capacitor: (a) grid voltage $v_{a n}(\mathrm{~V})$ and grid current $i_{a}(\mathrm{~A})(\mathrm{b}) \mathrm{PV}$ array current $i_{p v}(\mathrm{~A})$.

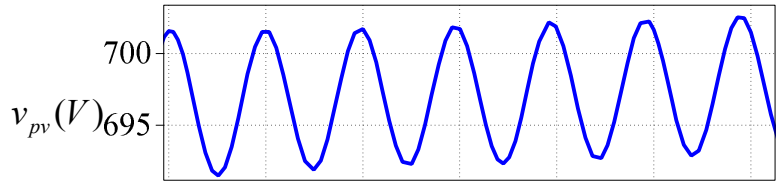

(a)

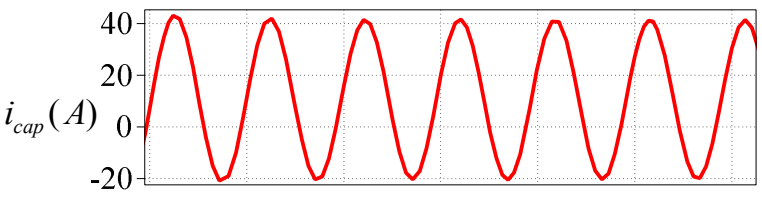

(b)

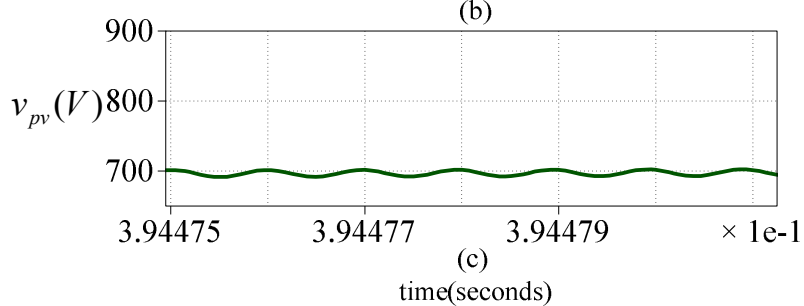

time(seconds)

Fig. 6. Simulation results Case II $-C_{d c}$ is $47-\mu \mathrm{F}$ film capacitor: (a) detailed view of dc-link voltage showing the ripple (b) capacitor current and (c) dclink voltage. 


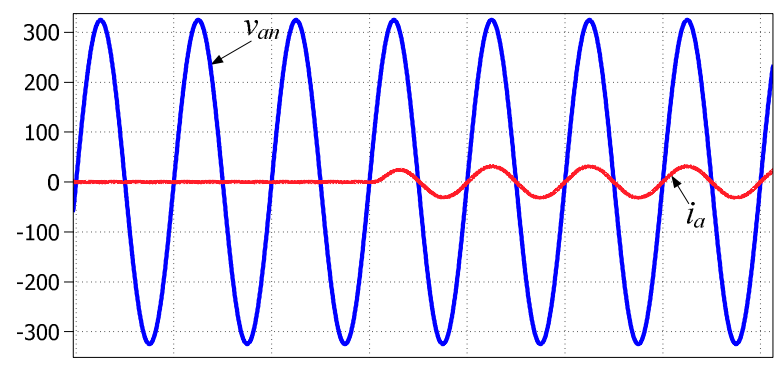

(a)

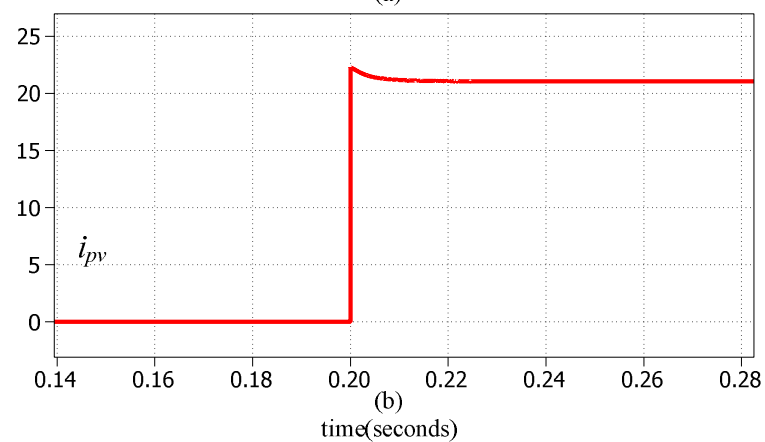

Fig. 7. Simulation results Case I - $C_{d c}$ is $2800-\mu \mathrm{F}$ electrolytic capacitor: (a) grid voltage $v_{a n}(\mathrm{~V})$ and grid current $i_{a}(\mathrm{~A})$ and (b) PV array current $i_{p v}(\mathrm{~A})$ for an increase in solar irradiance from $0 \mathrm{~kW} / \mathrm{m}^{2}$ to $1.0 \mathrm{~kW} / \mathrm{m}^{2}$.
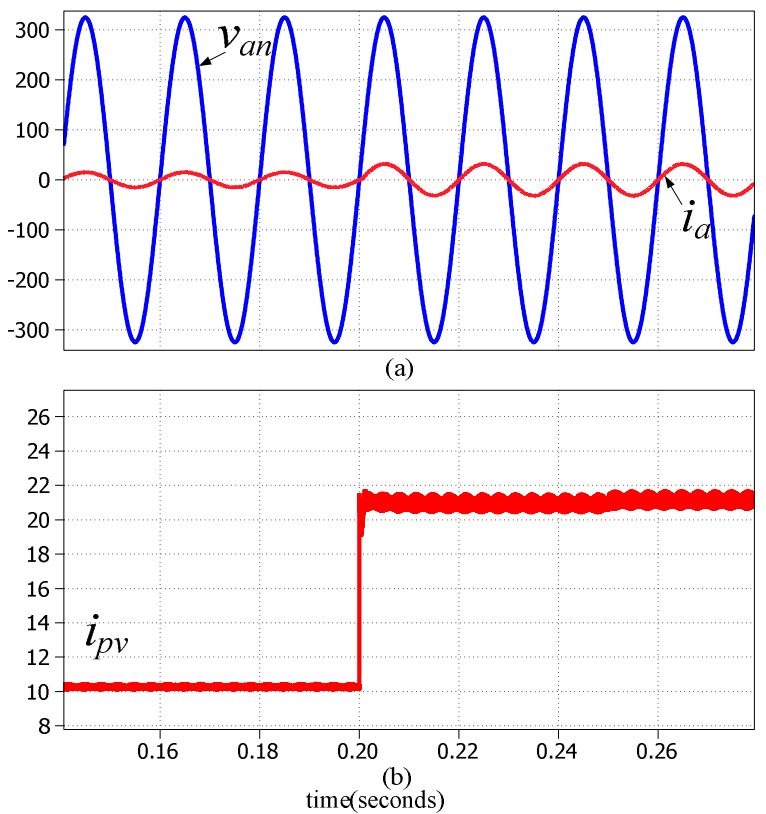

Fig. 8. Simulation results Case II $-C_{d c}$ is $47-\mu \mathrm{F}$ film capacitor: (a) grid voltage $v_{a n}(\mathrm{~A})$ and grid current $i_{a}(\mathrm{~A})$ and (b) PV array current $i_{p v}$ (A) for an increase in solar irradiance from $0 \mathrm{~kW} / \mathrm{m}^{2}$ to $1.0 \mathrm{~kW} / \mathrm{m}^{2}$.

\section{EXPERIMENTAL RESULTS}

The performance of the three-phase grid-connected inverter with electrolytic and film capacitors is verified with an experimental set-up in the laboratory. In the absence of a PV simulator, a dc power supply in the voltage source mode is used instead. The software controllers are implemented in dSPACE DS1104 controller residing in a Hewlett Packard workstation. An IGBT inverter with a switching frequency of
$10 \mathrm{kHz}$ is used. A three-phase step-down transformer with $415 \mathrm{~V} / 200 \mathrm{~V}$ is used to connect to the grid in the laboratory. A photograph of the experimental set-up is shown in Fig. 9. The parameters of the experimental set-up are in Table II. Experiments are conducted at $3.0 \mathrm{~kW}$ power level. The results are broadly classified as steady state and transient.

TABLE II. PARAMETERS OF THE THREE-PHASE PV-INVERTER UNDER EXPERIMENT STUDY

\begin{tabular}{|l|c|c|}
\hline Rated power of dc power supply & $P_{\max }$ & $3000 \mathrm{~W}$ \\
\hline Rated voltage of dc power supply & $V_{p v}$ & $400 \mathrm{~V}$ \\
\hline $\begin{array}{l}\text { DC capacitors (Electrolytic) (EPCOS type } 2 \\
\text { x B43564-A5228, 2200 } \mu \mathrm{F} \text { in series) }\end{array}$ & $C_{d c}$ & $1100 \mu \mathrm{F}$ \\
\hline $\begin{array}{l}\text { DC capacitors (metallized polypropylene } \\
\text { film) AVX type FFVE6C0476K, 900V dc }\end{array}$ & $C_{d c}$ & $47 \mu \mathrm{F}$ \\
\hline External line inductor & $L_{f}$ & $5 \mathrm{mH}$ \\
\hline Inverter switching frequency & $f_{s}$ & $10 \mathrm{kHz}$ \\
\hline
\end{tabular}

\section{A. Steady State}

\section{Results with 1100- $\mu$ F Electrolytic Capacitor}

The equivalent capacitance of $1100 \mu \mathrm{F}$ is achieved with two EPCOS type B43456-A5228 $2200 \mu \mathrm{F} / 450 \mathrm{~V}$ capacitors connected in series. The three-phase inverter is connected to the $415-\mathrm{V}$ grid through a $200 \mathrm{~V} / 415 \mathrm{~V}$ transformer and $380 \mathrm{~V}$ dc was applied to the dc input. The grid voltage $v_{a n}$, the grid current $i_{a}$ and power supply current $i_{p v}$ are recorded as shown in Fig. 10. The dc voltage and ripple voltage across the capacitor and the capacitor current are recorded as indicated in Fig. 11. The ripple voltage across the capacitor is close to $2 \mathrm{~V}$ at $380 \mathrm{~V}$ dc, which is $0.52 \%$ as seen in Fig. 11(a). The capacitor current $i_{\text {cap }}$ has a peak- peak value of $16 \mathrm{~A}$ as seen in Fig. 11(b).

\section{Results with 47- $\mu$ F Film Capacitor}

The two series-connected EPCOS 2200- $\mu \mathrm{F}$ electrolytic capacitors are replaced by an AVX type FFVE6C0476K, $900 \mathrm{~V}$ dc $47-\mu \mathrm{F}$ film capacitor and the steady state measurements are repeated as taken for $1100-\mu \mathrm{F}$ electrolytic capacitor. The grid voltage $v_{a n}$, grid current $i_{a}$ and power supply current $i_{p v}$ are recorded as shown in Fig. 12. The dc voltage and ripple voltage across the capacitor and the capacitor current $i_{\text {cap }}$ are recorded as indicated in Fig. 13. The ripple voltage is close to $9 \mathrm{~V}$ for a $380 \mathrm{~V}$ dc bus, which is $2.36 \%$ as seen in Fig. 13(a). The capacitor current has a peakpeak value of $32 \mathrm{~A}$ as seen in Fig. 13(b).

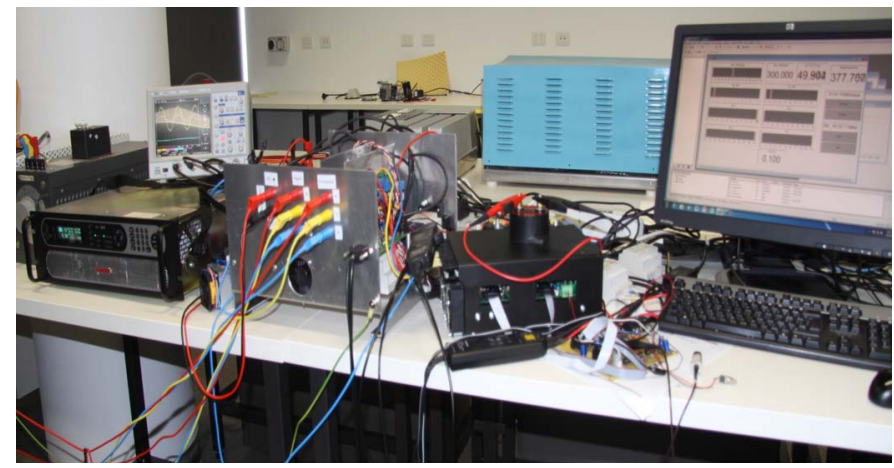

Fig. 9. Experimental set-up of the three-phase grid-connected PV-inverter. 


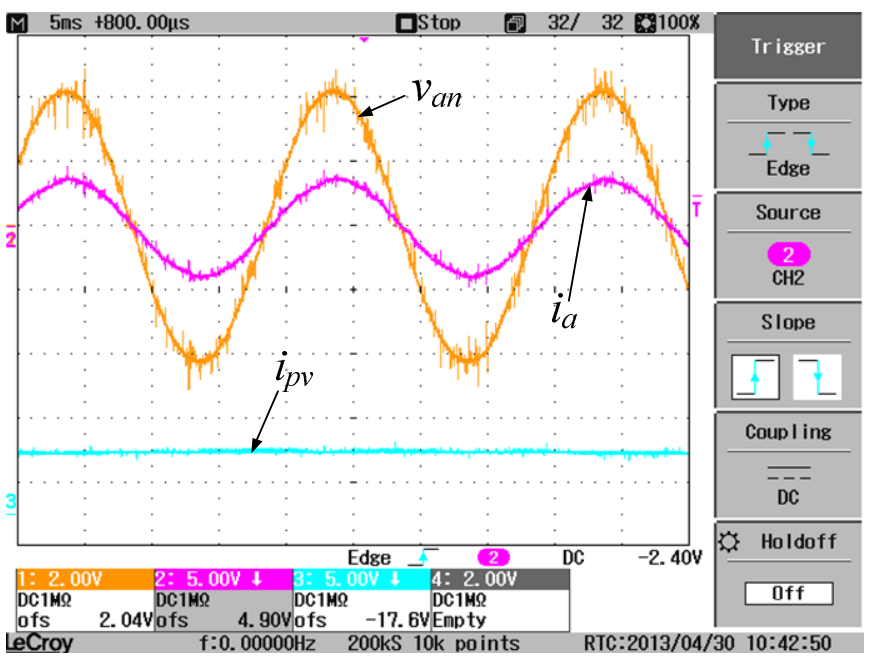

Fig. 10. Experimental results Case I - dc-link capacitor value of $1100 \mu \mathrm{F}$ electrolytic type: grid voltage $v_{a n}(80 \mathrm{~V} / \mathrm{div})$, grid current $i_{a}(15 \mathrm{~A} / \mathrm{div})$ and PV array current $i_{p v}(7.5 \mathrm{~A} / \mathrm{div})$.

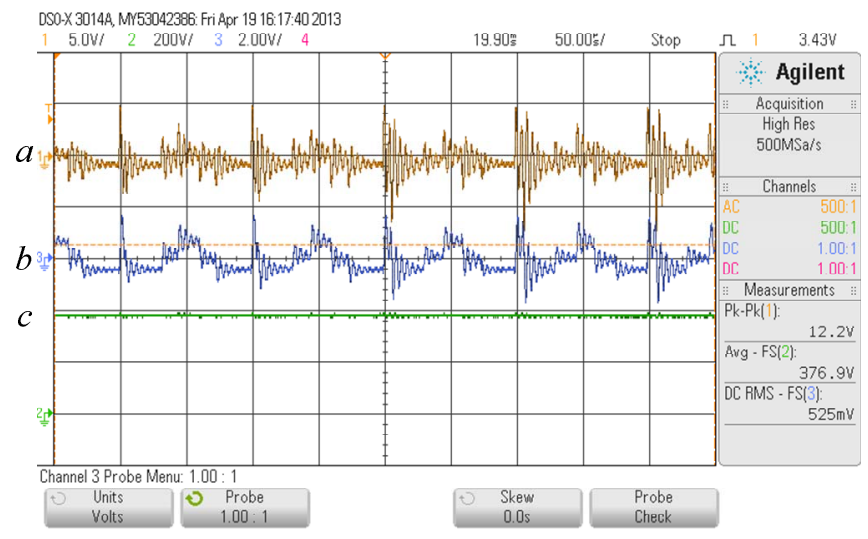

Fig. 11. Experimental results Case I - dc-link capacitor value of $1100 \mu \mathrm{F}$ electrolytic type: detailed view of the dc-link voltage $v_{p v}$ showing the ripple (5V/div), capacitor current $i_{c a p}(20 \mathrm{~A} / \mathrm{div})$ and dc-link voltage $v_{p v}(200 \mathrm{~V} / \mathrm{div})$.

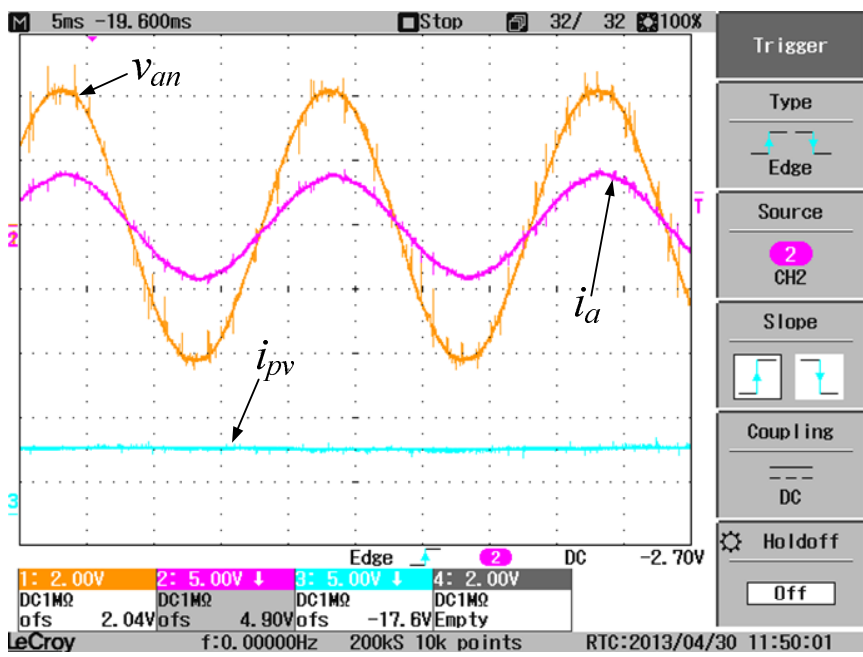

Fig. 12. Experimental results Case II - dc-link capacitor value of $47 \mu \mathrm{F}$ film type: grid voltage $v_{a n}(80 \mathrm{~V} / \mathrm{div})$, grid current $i_{a}(15 \mathrm{~A} / \mathrm{div})$ and dc input current $i_{p v}(7.5 \mathrm{~A} / \mathrm{div})$

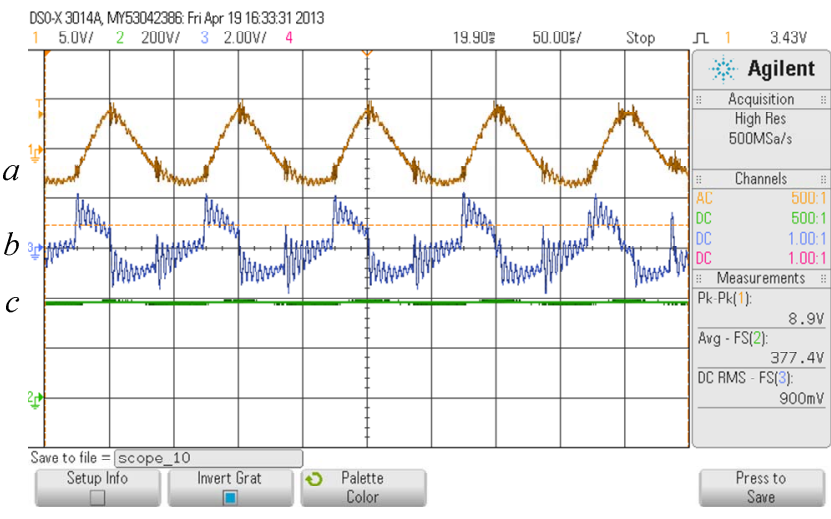

Fig. 13. Experimental results Case II - dc-link capacitor value of $47 \mu \mathrm{F}$ film type: detailed view of dc-link voltage $v_{p v}$ showing the ripple $(5 \mathrm{~V} / \mathrm{div})$, capacitor current $i_{c a p}(20 \mathrm{~A} / \mathrm{div})$ and dc-link voltage $v_{p v}(200 \mathrm{~V} / \mathrm{div})$.

\section{B. Transient}

The transient performance of the grid-connected inverter is verified after replacing the two series-connected $2200-\mu \mathrm{F}$ electrolytic capacitors in the inverter with one $47-\mu \mathrm{F}$ film capacitor.

\section{Results with 1100- $\mu$ F Electrolytic Capacitor}

The grid voltage $v_{a n}$, grid current $i_{a}$ and the input power supply current $i_{p v}$ are recorded for a step change in the dc input voltage from $0 \mathrm{~V}$ to $380 \mathrm{~V}$. The results are shown in Fig. 14. Also, the transient results are recorded for a step change in the dc input voltage from 380 $\mathrm{V}$ to $0 \mathrm{~V}$ as shown in Fig. 15. A smooth transition in the grid current is observed as seen in Fig. 15(b).

\section{Results with 47- $\mu$ F Film Capacitor}

The transient performance of the grid-connected inverter is compared after replacing the two series-connected $2200-\mu \mathrm{F}$ electrolytic capacitors with one $47-\mu \mathrm{F}$ film capacitor. One result is recorded for a step change in the dc input voltage

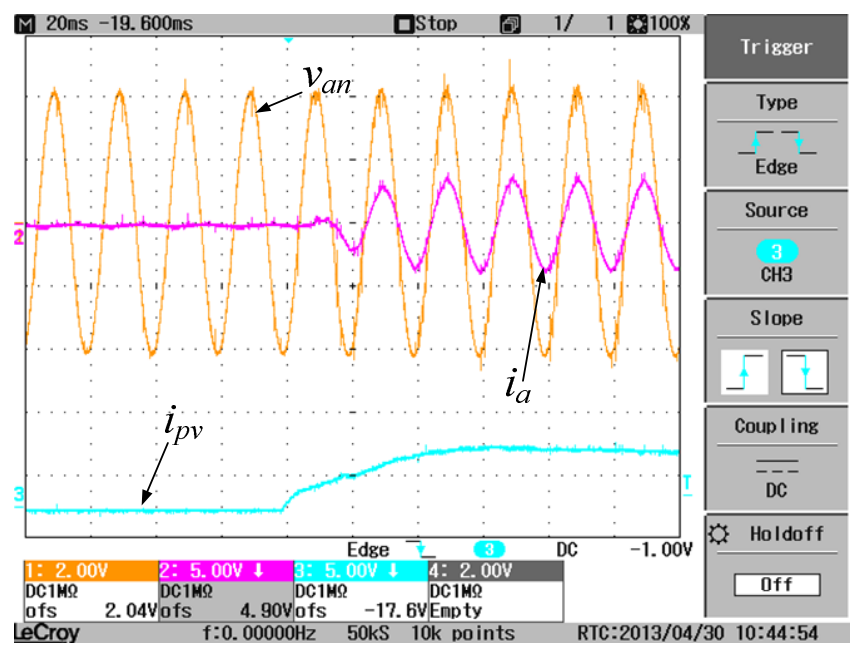

Fig. 14. Experimental results Case I - dc-link capacitor value of $1100 \mu \mathrm{F}$ electrolytic type: grid voltage $v_{a n}(80 \mathrm{~V} / \mathrm{div})$, grid current $i_{a}(15 \mathrm{~A} / \mathrm{div})$ and dc input current $i_{p v}(7.5 \mathrm{~A} / \mathrm{div})$ when the $380 \mathrm{~V}$ dc is switched on. 


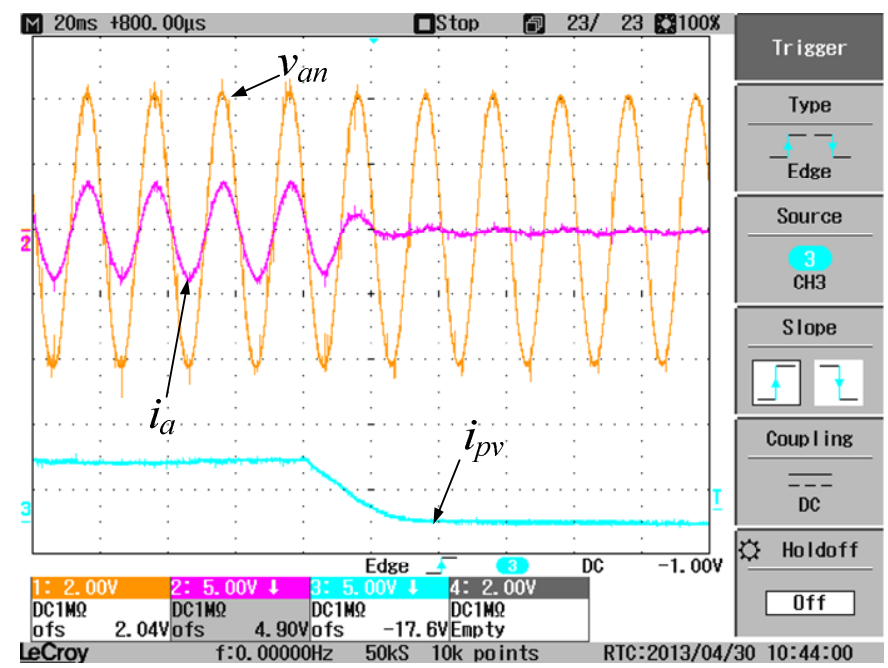

Fig. 15. Experimental results Case I - dc-link capacitor value of $1100 \mu \mathrm{F}$ electrolytic type: grid voltage $v_{a n}(80 \mathrm{~V} / \mathrm{div})$, grid current $i_{a}(15 \mathrm{~A} / \mathrm{div})$ and $\mathrm{dc}$ input current $i_{p v}(7.5 \mathrm{~A} / \mathrm{div})$ when the $380 \mathrm{~V}$ dc is switched off.

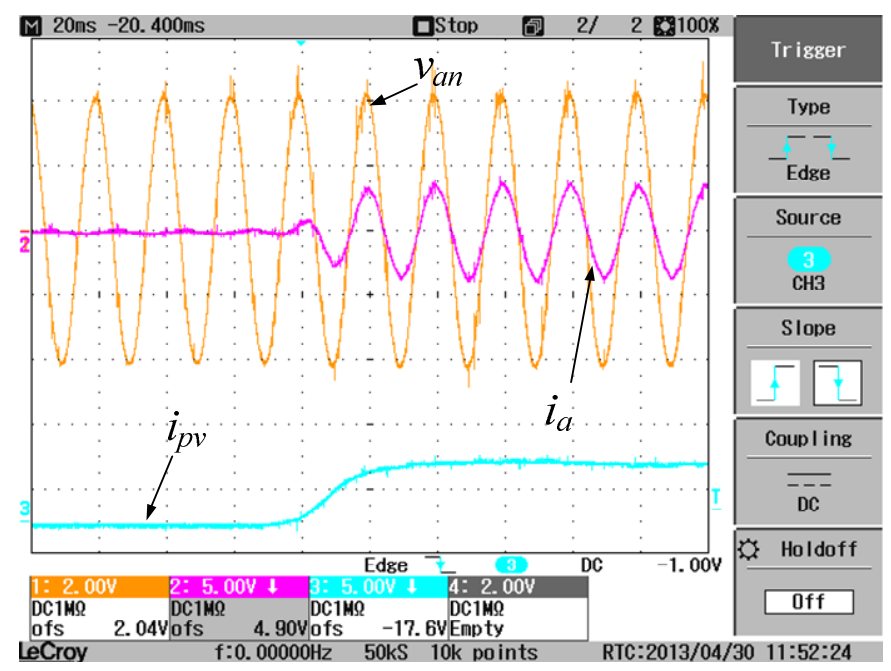

Fig. 16. Experimental results Case II - dc-link capacitor value of $47 \mu \mathrm{F}$ electrolytic type: grid voltage $v_{a n}(80 \mathrm{~V} / \mathrm{div})$, grid current $i_{a}(15 \mathrm{~A} / \mathrm{div})$ and $\mathrm{dc}$ input current $i_{p v}(7.5 \mathrm{~A} / \mathrm{div})$ when the $380 \mathrm{~V}$ dc is switched on.

from $0 \mathrm{~V}$ to $380 \mathrm{~V}$ as shown in Fig. 16. The test was repeated for a step change in the dc input voltage from $380 \mathrm{~V}$ to $0 \mathrm{~V}$ as shown in Fig. 17. The $47-\mu \mathrm{F}$ film capacitor is found adequate for this grid-connected three-phase inverter system.

\section{CONCLUSION}

A three-phase grid-connected PV-inverter with polypropylene film capacitor for dc-link decoupling has been presented in this paper. The aim is to extend the operating lifetime of the PV-inverter to match that of the PV panel.

The steady state and transient measurements carried out with grid-connected PV systems with electrolytic and film capacitors are found to be in close agreement that large dc-link electrolytic capacitors can be replaced by small film capacitors without compromising the system's performance.

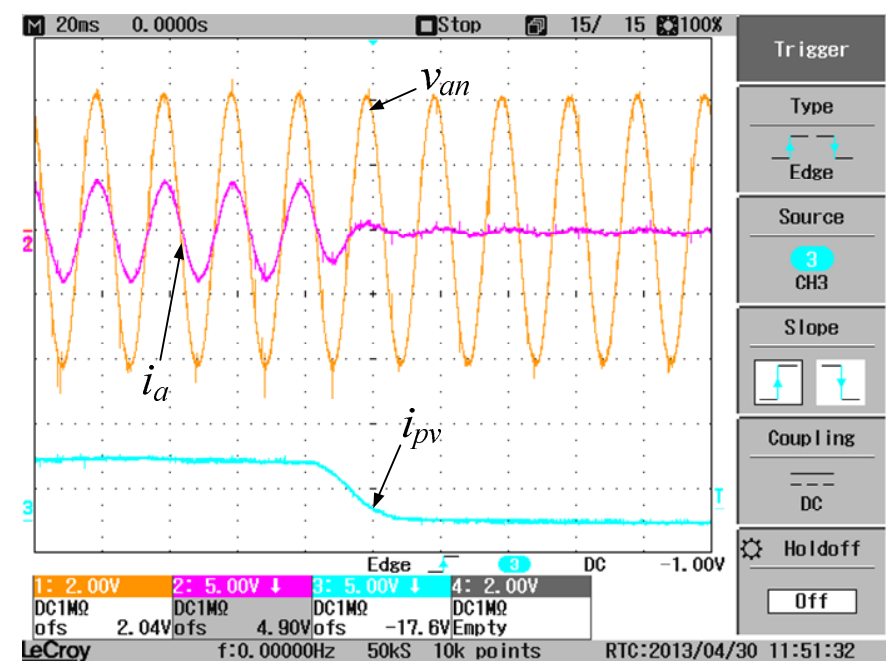

Fig. 17. Experimental results Case II - dc-link capacitor value of $47 \mu \mathrm{F}$ film type: grid voltage $v_{a n}(80 \mathrm{~V} / \mathrm{div})$, grid current $i_{a}(15 \mathrm{~A} / \mathrm{div})$ and dc input current $i_{p v}(7.5 \mathrm{~A} / \mathrm{div})$ when the $380 \mathrm{~V}$ dc is switched off.

In this case, the small increase in ripple in the dc current $i_{p v}$ and the ripple in the dc voltage $v_{p v}$ are within acceptable limits.

\section{REFERENCES}

[1] E. D. Dunlop, D. Halton, and H. A. Ossenbrink, "20 years of life and more: Where is the end of life of a PV module?," in Proc. Conf. Record IEEE Photovolt. Spec. Conf., 2005, pp. 1593-1596.

[2] P. Chaparala, E. Li, and S. Bhola, "Reliability qualification of photovoltaic smart panel electronics," in Proc. 17th IEEE Int. Symp. Phys. Failure Anal. Integr. Circuits, Jul. 2010, pp. 1-4.

[3] H. R. Andersen, Ruimin Tan, and Cai Kun, "3-phase AC-drives with passive front-ends with focus on the slim DC-link topology," in Proc. Power Electronics Specialists Conference, 2008, pp. 3248-3254.

[4] R. Maheshwari, S. Munk-Nielsen, and S. Busquets-Monge, "Design of neutral-point voltage controller of a three-level NPC inverter with small DC-link capacitors," IEEE Trans. Ind. Electron., Vol. 60, no. 5, pp 1861-1871, May 2013.

[5] EPCOS, "Film Capacitors - Reliability with a long operating life," Components, Application \& Cases, Edition 2-07.

[6] F. Schimpf and L. Norum, "Effective use of film capacitors in singlephase PV-inverters by active power decoupling," in Proc. IEEE IECON 2010, pp 2784-2789, Nov. 2010.

[7] J. Schonberger, "A single phase multi-string PV inverter with minimal bus capacitance," in Proc. of European Conference on Power Electronics and Applications, pp. 1-10, Sep. 2009.

[8] Gab-Su Seo, Bo-Hyung Cho, and Kyu-Chan Lee, "Electrolytic capacitor-less PV Converter for full lifetime guarantee interfaced with DC Distribution," in Proc. IEEE Power Electronics and Motion Control Conference (IPEMC), pp 1235-1240, Jun. 2012.

[9] M. Salcone and J. Bond, "Selecting film bus link capacitors for high performance inverter applications," in Proc. of IEEE Electric Machines and Drives Conference, pp 1692-1699, May 2009.

[10] H. Wen, W. Xiao, X. Wen, and P. Armstrong "Analysis and evaluation of DC-link capacitors for high-power-density electric vehicle drive systems," in IEEE Trans. Vehicular Technology, vol. 61, no. 7, pp 2950-2964, Sep. 2012.

[11] J.W. Kolar and S.D. Round, "Analytical calculation of the RMS current stress on the DC-link capacitor of voltage PWM converter systems," in Proc. Inst.Elect.Eng.-Elect. Power Appl., vol. 153, no. 4, pp 535-543, Jul. 2006.

[12] F. Blaabjerg, R. Teodorescu, M. Liserre, and A.V. Timbus, "Overview of control and grid synchronization for distributed power generation systems," IEEE Trans. Ind. Electron., vol. 53, no. 5, pp 1389-1409, Oct. 2006. 